\title{
Clinicians are leading service reconfiguration to cope with covid-19
}

\author{
It's not just the Nightingale hospitals-clinically led reorganisation is transforming how trusts are \\ working, finds Jacqui Thornton
}

\author{
Jacqui Thornton
}

London

As the NHS Nightingale hospitals attract widespread publicity, ${ }^{1}$ clinically led innovation is quietly-and quickly-transforming practice in acute trusts to cope with covid-19.

Across the UK, the pace of change has been "breathtaking," says Keith Girling, medical director at Nottingham University Hospitals NHS Trust. It's not just the huge increase in intensive care capacity, there is also the reconfiguration of wards to accommodate more patients and redeployment of staff within those areas.

Medical teams are working in completely different ways, with consultant led and delivered care provided around the clock; rotas have been rewritten wholesale; and areas of trusts that are quieter, such as clinical genetics and genitourinary medicine, are lending trainees and equipment to be used in imaginative ways, with consultants picking up the baseline.

At the same time, IT proposals that before the outbreak were expected to take months have been accelerated and have come to fruition in days, and new clinical pathways have developed at record speed. This has happened at district general and large teaching hospitals alike. And, crucially, says David Oliver, consultant in geriatrics and acute general medicine at the Royal Berkshire NHS Foundation Trust and a columnist for The BMJ, much of this work was going on well before guidance from central bodies.

\section{West Hertfordshire: breaking down barriers}

Andrew Barlow, respiratory consultant and divisional director for medicine at West Hertfordshire Hospitals NHS Trust, says, "I've been blown away by the innovation both in terms of working together and doing rotas in a different way and of breaking down barriers between specialties. I don't think the respiratory and [intensive care] departments have ever been closer-we sense check with them and vice versa."
In one clinical innovation at West Hertfordshire, the radiology department has transformed the way its teams are working, with IT support enabling its consultants to report virtually from home overnight.

The trust is particularly proud of its "virtual warriors." These are clinicians who really want to contribute but because of their vulnerable status cannot do patient facing work-so many are doing backroom functions supporting the front line. Consultants are also carrying out consultations by phone to prevent unnecessary admissions and reduce patient anxiety.

Barlow says that they had a head start on covid-19 by last year introducing the SMART system, in which cardiology and respiratory consultants join the on-call general medicine consultant in the emergency department between 9am and 9pm.

Mike van der Watt, chief medical officer at the trust, says, "It was working extremely well and then with the challenge of covid-19 it was easy to bolster up the respiratory side. All we had to do was partition the emergency department into two separate areas." He accepts that all the changes and the anticipation of the surge has led to some staff nervousness but adds, "They are dealing with it with really good cheer."

\section{Nottingham: "mega rotas"}

At Nottingham University Hospitals NHS Trust, Girling says that the changes have been "pretty high octane." One clinical innovation has been the creation overnight of a respiratory advice line rota, staffed by senior respiratory physicians, which gives advice to GPs, paramedics, and hospital doctors across the region.

It enables direct access to a senior consultant, prevents inappropriate referrals, and reduces anxiety in the community. The first week saw a peak of 160 daily calls to the advice line, of which $60 \%$ were from ambulance staff, $20 \%$ hospital doctors, $10 \%$ GPs and 10\% from NHS 111. 
John Walsh, consultant cardiologist at Nottingham, says that as a clinical manager the changes have been a "revelation." He says, "We have managed to integrate nearly 1200 medical staff of all grades to provide a 'mega rota' coordinating care and educating each other across usual boundaries and silos to deliver a united effort to cope with service demand.

"The medical and surgical divisions are now effectively functioning as a single department with new structures implemented in days that ordinarily would take months."

\section{Video clinics, home working, adapted wards}

At Southampton University NHS Foundation Trust, more than 90 outpatient services have been set up to run as video clinics, amounting to 300 consultations a week. The trust has enabled at-scale home working, with 758 of 1412 requests for home working by consultants and other clinical and administrative staff approved. Microsoft Teams has been established for all staff for remote meetings and multidisciplinary teams, with a results channel, which provides senior nursing staff and infection control teams with live results on inpatients testing positive for covid-19.

At the district general hospital level, Homerton University Hospital in east London has seen its intensive care capacity triple in 10 days. "It's like having a major incident every day for the past two weeks, and we don't know how long it's going to go on for," says a spokesperson. The hospital is caring for 168 patients with covid-19 in six specially adapted wards with bed bays that can be isolated with glass screens. "We have turned from a district general hospital into a focused covid hospital overnight," the spokesperson says.

Chaand Nagpaul, BMA council chair, says that it is important to acknowledge all this work-not just the NHS Nightingale hospitals. He says, "While the NHS is increasing capacity in brand new covid-19 hospitals, it's vital that we also recognise the transformational efforts of doctors in each and every hospital throughout the UK to meet the escalating demands of the pandemic on the NHS.

"Doctors are rapidly learning new skills—many shifting from their normal specialty to focus on new areas of need. The NHS is doing all it can to tackle covid-19, and doctors across the nation are showing immense courage, determination, and leadership in preparing their hospitals to cope with the relentless pressures ahead."

Competing interests: I have read and understood BMJ policy on declaration of interests and have no relevant interests to declare

Provenance and peer review: Commissioned; not externally peer reviewed.

1 Moberly T. From conference centre to hospital. BMJ 2020;368:m1298. 10.1136/bmj.m1298 32234731

Published by the BMJ Publishing Group Limited. For permission to use (where not already granted under a licence) please go to http://group.bmj.com/group/rights-licensing/ permissions 